\title{
Mechanism and consequences of RAF kinase activation by small-molecule inhibitors
}

\author{
M Holderfield ${ }^{1}$, T E Nagel ${ }^{2}$ and D D Stuart ${ }^{\star}, 2$ \\ ${ }^{1}$ UCSF Helen Diller Family Comprehensive Cancer Research, University of California San Francisco, San Francisco, CA 94143-0128, \\ USA and ${ }^{2}$ Novartis Institutes for Biomedical Research, Emeryville, CA 94523, USA
}

Despite the clinical success of RAF inhibitors in BRAF-mutated melanomas, attempts to target RAF kinases in the context of RAS-driven or otherwise RAF wild-type tumours have not only been ineffective, but RAF inhibitors appear to aggravate tumorigenesis in these settings. Subsequent preclinical investigation has revealed several regulatory mechanisms, feedback pathways and unexpected enzymatic quirks in the MAPK pathway, which may explain this paradox. In this review, we cover the various proposed molecular mechanisms for the RAF paradox, the clinical consequences and strategies to overcome it.

Sorafenib was the first RAF kinase inhibitor to enter human clinical trials in 1999. At that time the therapeutic hypothesis was that RAS mutant tumours could be treated by inhibiting a 'druggable' downstream node in the RAF-MEK-ERK pathway. Unfortunately, this therapeutic hypothesis was never effectively tested, as sorafenib is a more potent inhibitor of the angiogenic kinases (VEGFR, PDGFR), which likely drives the therapeutic efficacy in tumours such as hepatocellular carcinoma and renal cell carcinoma that lack mutations in RAS and BRAF (Wilhelm et al, 2004).

Discovery of the BRAF oncogenes marked a significant shift in RAF inhibitor drug development. The second-generation RAF inhibitors such as vemurafenib, dabrafenib and LGX818 were developed specifically to inhibit the RAF-MEK-ERK pathway signalling in cells expressing the $B R A F^{V 600 E}$ oncogene. These drugs potently inhibit MEK phosphorylation and growth of $\mathrm{BRAF}^{\mathrm{V} 600 \mathrm{E}}$ mutated melanoma cells, and are highly effective at inducing tumour regression in melanoma patients. Vemurafenib and dabrafenib are approved for the treatment of metastatic melanoma based on overall response rates of over $50 \%$ and significant improvements in progression-free and overall survival (Chapman et al, 2011b; Hauschild et al, 2012). Although sorafenib, vemurafenib, dabrafenib and LGX818 are all ATP-competitive kinase inhibitors, sorafenib stabilises the enzyme with the DFG-loop flipped out of the ATP pocket (Type 2-binding mode), whereas the other inhibitors stabilise the enzyme with the DFG-loop in the ATP pocket (Type 1-binding mode) (Liu and Gray, 2006). All of these inhibitors are less-potent inhibitors of RAF-MEK-ERK signalling in cells expressing wild-type BRAF and in fact paradoxically activate the pathway, especially in cells with activating RAS mutations.

\section{PARADOXICAL RAF ACTIVATION}

The first evidence that RAF inhibitors could activate RAF kinases was published in 1999 by Hall-Jackson et al (1999) who showed that cells exposed to an ATP-competitive RAF inhibitor, ZM336372, paradoxically increased activity of RAF kinase. Although ZM336372 effectively inhibited purified BRAF and CRAF in vitro, the compound failed to suppress MEK phosphorylation in cells. Drug wash-out experiments indicated that ZM336372 promoted MEK phosphorylation upon removal of the inhibitor. This effect was reduced by pre-treatment with a MEK inhibitor, suggesting that the paradoxical activation of RAF is mediated by a downstream effector(s). The authors concluded that RAF kinases suppress their own activation by engaging feedback loops in a MEK-dependent manner and several examples of feedback mechanisms have since been characterised. ERK activation promotes transcription of DUSP phosphatases and SPRY1 (Pratilas et al, 2009; Lito et al, 2012), which both attenuate RAF activation. Activated ERK itself has also been shown to directly inhibit BRAF and CRAF through phosphorylation sites that prevent BRAF-CRAF heterodimerisation and interaction with activated RAS (Dougherty, 2005; Ritt et al, 2010). These mechanisms are particularly apparent in cells treated with MEK inhibitors, which abrogate ERK phosphorylation, but increase activity of RAF kinases, and in some cases, promote

*Correspondence: Dr DD Stuart; E-mail: darrin.stuart@novartis.com

Received 19 November 2013; revised 18 February 2014; accepted 24 February 2014;

published online 18 March 2014

(C) 2014 Cancer Research UK. All rights reserved 0007 - 0920/14

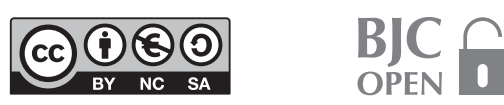


phosphorylation of MEK itself (Ishii et al, 2013). Although there is clear evidence for the existence of feedback loops in the paradoxical activation observed by Hall-Jackson et al (1999), more recent studies implicate an intrinsic ability of ATP-competitive inhibitors to activate RAF kinases (Hatzivassiliou et al, 2010; Heidorn et al, 2010; Poulikakos et al, 2010).

\section{CRAF DEPENDENCE}

The existence of kinase-impaired BRAF mutations in human cancer may have provided an early clue to the mechanism by which RAF inhibitors stimulate the RAF-MEK-ERK pathway in cells. Wan et al (2004) characterised the activity of $\mathrm{BRAF}^{\mathrm{V} 600 \mathrm{E}}$ and several other BRAF mutants, which predominantly reside in the activation loop (positions 594-601) or the phosphate-binding loop (positions 464-469). These domains interact when the enzyme is in the inactive conformation, and the V600E mutation shifts the kinase into the active conformation, suggesting that disrupting this interaction is a primary mechanism for activating the $B R A F$ oncogenes. However, not all of the mutations result in increased enzymatic activity. Many render BRAF catalytically inactive, yet increase the MEK phosphorylation through transactivation of CRAF (Garnett et al, 2005). This phenomenon is particularly exaggerated in the context of a KRAS oncogene, and is phenocopied in BRAF wild-type cells treated with BRAF-selective inhibitors. This finding suggested that BRAF acts to suppress CRAF activity and that selective suppression of BRAF catalytic activity activates the MAPK pathway in a CRAF-dependent manner.

\section{RAS DEPENDENCE}

Although inactivating BRAF mutations are observed in some human cancers, they appear to be relatively weak oncogenes, and are somewhat rare. Inducible expression of either KRAS ${ }^{\mathrm{G} 12 \mathrm{D}}$ or the kinase dead $B R A F^{D 594 A}$ oncogene in mouse skin were both insufficient to cause melanocytic tumours alone, yet co-occurrence of both mutations caused rapid cutaneous tumorigenesis (Heidorn et al, 2010). Similarly, RAF inhibitors cause fairly modest MAPK pathway activation in KRAS wild-type cells, but marked MEK phosphorylation and increased proliferation in KRAS-mutated cells in a KRAS-dependent manner. RAF inhibitors also cause membrane localisation of CRAF, where it engages RAS-GTP and becomes phosphorylated at S338, events associated with activation (Hatzivassiliou et al, 2010). However, interaction with RAS-GTP may not be the only mechanism involved in the RAF paradox. Expression of a truncated form of CRAF, which lacks the RASbinding domain is sufficient for RAF inhibitor-induced MAPK activity in cells (Poulikakos et al, 2010) and in a cell-free system (Holderfield et al, 2013), suggesting that although RAS-GTP may enhance the ability of RAF inhibitors to activate full-length RAF in cells, there is also a RAS-independent mechanism that is intrinsic to the RAF kinase domain.

\section{DRUG-INDUCED DIMERISATION}

Another critical observation from the BRAF-sorafenib co-crystal structure was that RAF kinase domains exist in a dimeric complex (Wan et al, 2004). Although the structure of the isolated monomeric enzyme remains unknown, several crystal structures exist for the RAF kinase domain in complex with ATP-competitive RAF inhibitors. Occupation of the ATP pocket appears to order the kinase domains (Wan et al, 2004) in 'side-to-side' dimers through arginine residues near the alpha-C helix (Rajakulendran et al, 2009). Inhibitor-induced dimerisation is also observed in cells, as several RAF inhibitors promote co-immunoprecipitation of ARAF, BRAF, CRAF and KSR (McKay et al, 2011). Structurefunction studies also demonstrated that the dimer interface is physiologically relevant and required for full RAF kinase activity. Induced dimerisation of cytoplasmic CRAF alone is sufficient to stimulate MEK phosphorylation, suggesting that drug-induced dimerisation may have a role in RAF activation. However, the 'type 2' inhibitors such as sorafenib and AZ-628 readily promote dimerisation yet only modestly stimulate activity (Hatzivassiliou et al, 2010), suggesting that an additional allosteric mechanism imparted by a compound-binding mode also contributes.

The mechanism of RAF activation through dimerisation has long been a mystery. Dimerisation likely occurs at the intracellular membrane upon recruitment to RAS-GTP. RAS binding is thought to unfold the N-terminal regulatory domain of RAF (Stokoe and McCormick, 1997), expose the kinase domain, allow dimerisation and promote phosphorylation of the required residues (Marais et al, 1995). However, an additional allosteric mechanism is likely involved as not all RAF dimers are equivalent. BRAF/CRAF heterodimers appear to be most active, relative to BRAF or CRAF homodimers (Rushworth et al, 2006), suggesting that the conformation of the dimer affects activity. Dimerisation is also likely asymmetric, meaning that one RAF molecule acts as a scaffold to facilitate activation of the dimer partner ( $\mathrm{Hu}$ et al, 2013). RAF inhibitors seem to mimic this process by conferring an active conformation by binding in the active site, inducing dimerisation and transactivating the other RAF molecule (Poulikakos et al, 2010). This may explain why the inhibitorbinding mode affects the 'paradoxical activation' observed.

\section{AUTOPHOSPHORYLATION}

RAF dimerisation is also associated with multiple phosphorylation events, most notably of the activation loop (BRAF T598/S601 and CRAF T491/S494) and the CRAF N-terminal acidic motif (S338, Y340 and Y341), which are essential for kinase activity (Mason et al, 1999). CRAF S338 phosphorylation appears to correlate closely with CRAF activity and most likely occurs upon recruitment to RAS-GTP, although the activating kinase(s) are unknown and it is unclear exactly how this process is regulated apart from membrane localisation. It has recently been proposed that activation-loop phosphorylation occurs though cis-phosphorylation upon dimerisation ( $\mathrm{Hu}$ et al, 2013), indicating that the allosteric function of RAF dimers may be to facilitate autophosphorylation of the activation loop. In this model, RAF inhibitors facilitate RAF dimerisation and promote auto-activation of the dimerised RAF molecule not bound by the inhibitor.

Recently, our lab has demonstrated an additional kinasedependent mechanism contributing to 'paradoxical activation' and may explain why BRAF oncogenes and wild-type RAF enzymes respond so differently to catalytic inhibitors (Figure 1) (Holderfield et al, 2013). We identified an autophosphorylation site in the phosphate-binding loop that, when phosphorylated, markedly impairs kinase function. By contrast, preventing P-loop autophosphorylation either by mutating the P-loop or by addition of a catalytic RAF inhibitor elevates RAF kinase activity in vitro and in cells. As predicted, $B R A F^{V 600 E}$ and $B R A F$ oncogenes with point mutations in the P-loop bypass the auto-inhibitory effect, and RAF inhibitors do not activate the RAF-MEK-ERK pathway in cancer cells with these mutations, despite the presence of a co-occurring KRAS mutation. Because P-loop autophosphorylation of RAF is intrinsically linked to RAF catalytic activity, this mechanism predicts that all catalytic RAF inhibitors are likely to exhibit some 'paradoxical' activation of the MAPK pathway in RAS-mutated, BRAF wild-type cells. 


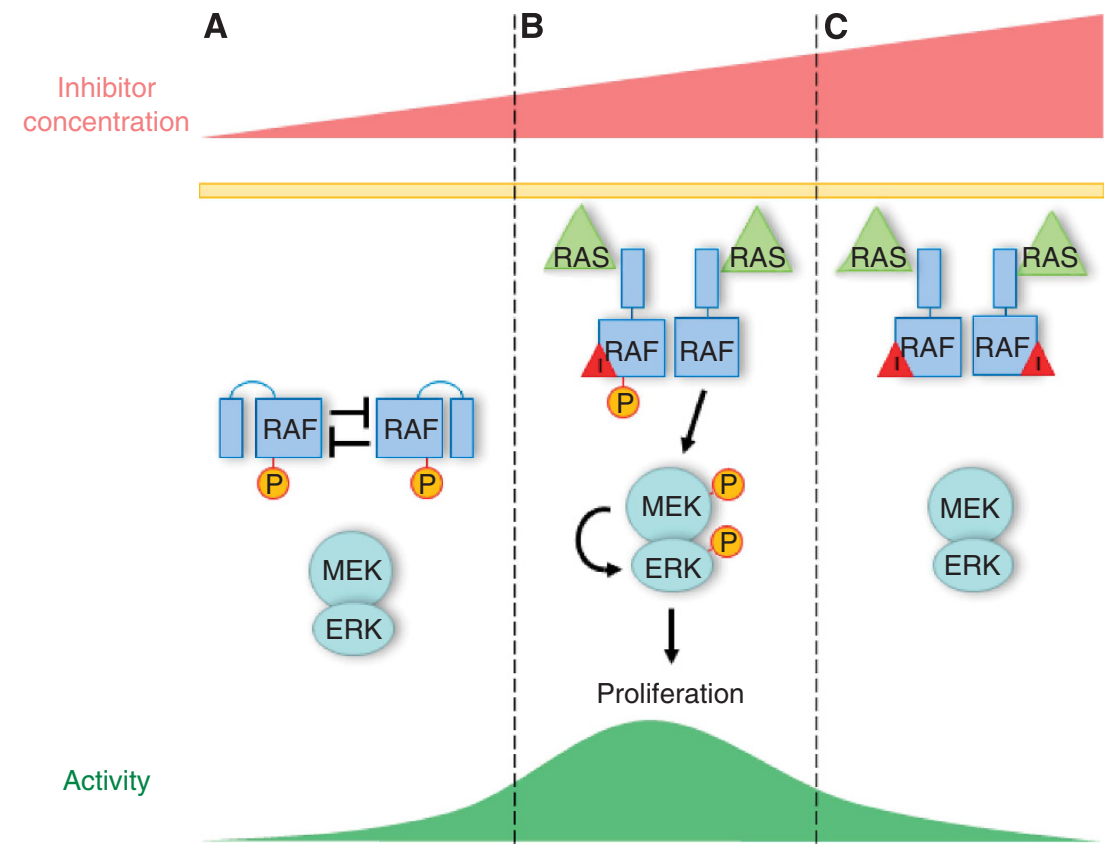

Figure 1. Role of inhibitory autophosphorylation in paradoxical activation by RAF kinase inhibitors. (A) RAF kinase activity is held in check through inhibitory autophosphorylation, potentially in trans, in RAF dimers. (B) Low concentration of a small-molecule RAF kinase inhibitor inhibits one RAF protomer, preventing it from phosphorylating the other protomer. The combination of loss of inhibitory phosphorylation and allosteric effects between the two RAF protomers results in increased kinase activity. (C) At higher concentrations the RAF kinase inhibitor binds and inhibits both RAF protomers and kinase activity is decreased.

\section{CLINICAL IMPLICATIONS}

Patients treated with vemurafenib and dabrafenib exhibit a variety of proliferative and malignant cutaneous lesions, and these side effects are consistent with paradoxical activation of wild-type BRAF as the underlying mechanism (Figure 2). Cutaneous squamous cell carcinomas (cSCC) and keratoacanthomas (KA) were the first dermatologic lesions described and recent studies indicate that these tumours frequently contain RAS mutations (Oberholzer et al, 2012; Su et al, 2012). Among the selective RAF inhibitors, there appears to be a difference in the incidence of cSCC, with dabrafenib studies reporting 6-11\% rates, whereas vemurafenib trials report $20-26 \%$, and in a recent phase I study with LGX818, only 1 out of 26 RAF inhibitor naive patients developed cSCC (Dummer et al, 2013; Menzies et al, 2013). It has been speculated that the lower incidence of cutaneous lesions seen with dabrafenib is owing to higher potency against $\mathrm{BRAF}^{\mathrm{V} 600 \mathrm{E}}$ compared with WT BRAF and CRAF, whereas vemurafenib may be relatively equipotent (Hauschild et al, 2012; Menzies et al, 2013). Another hypothesis is that off-target kinase inhibition contributes to the induction of cSCC. Specifically, inhibition of ZAK kinase, a component of the JNK pathway, prevents $\mathrm{UV}$-induced apoptosis and cooperates with paradoxical activation to induce cSCC (Vin et al, 2013). This hypothesis is particularly attractive in that the differences in incidence of cSCC could be explained by differences in off-target kinase profiles, and data in support of this hypothesis are provided by (Vin et al, 2013). It would also be consistent with the observation that cSCC still occur, although at lower frequency, in patients treated with a RAF plus MEK inhibitor combination (Cebon et al, 2013). In these cases, the MEK inhibitor should suppress the downstream consequences of RAF activation and thus suggesting the involvement of another signalling pathway. Of course all of these factors have to be considered in the context of drug pharmacokinetics and tissue distribution, which could have a role in the differences observed between the inhibitors.

Fortunately, cSCC/KA lesions pose a relatively low risk to melanoma patients and can be readily treated by excision. In addition to sSCC and KA, the other types of cutaneous side effects have been associated with RAF inhibitor treatment, such as hyperkeratosis, papillomas, palmar/plantar erythrodysaesthesia, photosensitivity, panniculitis, follicular cysts and basal cell carcinoma (Hauschild et al, 2012; Long et al, 2012; Zimmer et al, 2012; Ascierto et al, 2013; Boussemart et al, 2013). Changes in preexisting nevi have also been noted, with increases in pigmentation and size, as well as dysplastic alterations (Zimmer et al, 2012; Cohen et al, 2013).

More concerning are the recent reports of new primary melanomas arising in patients treated with vemurafenib or dabrafenib (Dalle et al, 2011; Chapman et al, 2011a; Boussemart et al, 2013). This is perhaps best exemplified in the well-controlled study by Zimmer et al (2012) in which 22 new or altered cutaneous melanocytic lesions were evaluated in V600-mutant BRAF metastatic melanoma patients who had received RAF inhibitor treatment. Of the analysed lesions, 12 were identified as newly developed primary melanomas, and 11 of those 12 were found to contain wild-type BRAF (results for the 12th were apparently inconclusive), with one found to contain mutant NRAS. In addition, 12 new or significantly altered nevi were removed during the course of the BRAF inhibitor treatment, and of the 9 that were evaluable, all contained wild-type BRAF, with 2 having NRAS mutations. As control samples, 22 common nevi were analysed from patients with no history of malignant melanoma or of BRAF inhibitor treatment. In these lesions, a substantial subset of these control nevi $(36 \%)$ had the $\mathrm{BRAF}^{\mathrm{V} 600 \mathrm{E}}$ mutation and all were wild-type for NRAS. This study, taken together with numerous others, supports the hypothesis that RAF inhibitors enhance dysplastic changes and malignant growth specifically in WT BRAF cells, and cells expressing mutant RAS. 

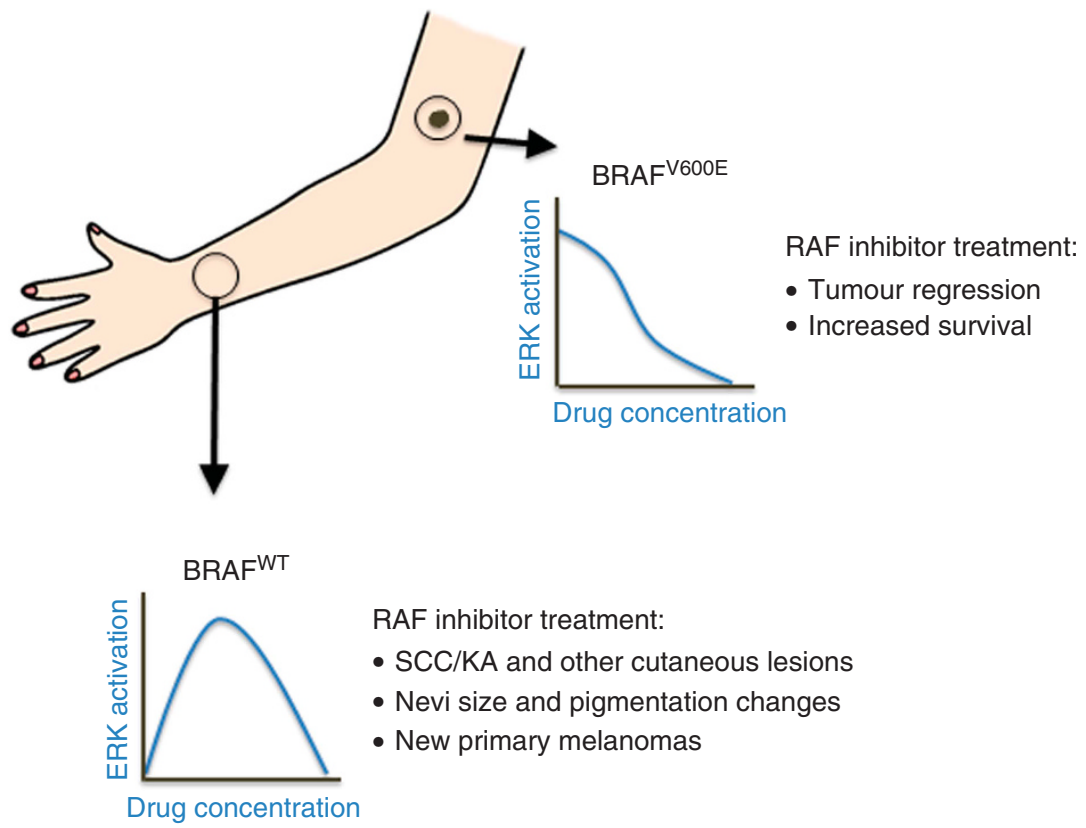

Figure 2. In melanoma tumours expressing the $B R A F^{V 6 O 0 E}$ oncogene RAF inhibitor treatment decreases ERK activation resulting in tumour regression and increased survival. In skin cells expressing wild-type BRAF, sometimes with underlying RAS mutations, RAF inhibitor treatment results in increased ERK activation leading to the formation of cutaneous lesions and/or changes to existing nevi. Arm picture modified from: http://www.carmenlu.com/first/vocabulary/health1/body1_1/body1_1.htm.

There have also been reports of progression of non-cutaneous lesions in BRAF inhibitor-treated patients. Chapman et al (2012) described the occurrence of pre-malignant colonic adenomas and gastric polyps in three vemurafenib-treated patients. Although these lesions were all non-malignant, their frequency reportedly exceeds that typically observed in similar patient populations. The acceleration or development of true malignancies has been described in two patients. In both cases, which included a leukaemia patient and a colorectal cancer patient, the tumours contained WT BRAF together with mutant RAS mutations (Andrews et al, 2012; Callahan et al, 2012). Although the causative role of BRAF kinase inhibition in these cases was not directly proven, analyses of the drug-induced signalling alterations in the specific cancer cells were consistent with the molecular mechanism of WT BRAF activation by BRAF inhibitors.

The difference in the pharmacological effect of RAF inhibitors in cells expressing wild-type $v s \mathrm{BRAF}^{\mathrm{V} 600 \mathrm{E}}$ also has the potential to impact therapeutic efficacy. For example, acquired resistance to RAF inhibitor treatment can result from the acquisition of activating NRAS mutations (Nazarian et al, 2011; Poulikakos et al, 2011). As described above, this would result in reactivation of the pathway through wild-type BRAF and CRAF, an effect that could be amplified by the presence of a RAF inhibitor. Furthermore, genetic heterogeneity in melanoma tumours can lead to discordance in BRAF mutational status between different metastases in the same patient (Heinzerling et al, 2013). In such cases treatment, with a RAF inhibitor would be expected to result in a mixed response, with $\mathrm{BRAF}^{\mathrm{V} 600}$ mutation-positive metastases responding to treatment and BRAF wild-type metastases failing to respond or even accelerating growth rate.

\section{OVERCOMING PARADOXICAL ACTIVATION}

One obvious strategy to overcome the activation of RAF-MEKERK signalling induced by the paradoxical activation of RAF would be to include a MEK inhibitor or ERK inhibitor as a combination partner. The combination of the RAF inhibitor dabrafenib with the MEK inhibitor trametinib was the first such combination tested in humans (Flaherty et al, 2012). Dabrafenib (150 mg per day) as a single agent (SA) or in combination with two different doses of trametinib ( $1 \mathrm{mg}$ per day or $2 \mathrm{mg}$ per day) was evaluated in a phase III study in patients with metastatic melanoma whose tumours harboured $\mathrm{BRAF}^{\mathrm{V} 600 \mathrm{E} / \mathrm{K}}$ mutations. Compared with SA dabrafenib, the combination $(\mathrm{C})$ treatment induced less skin toxicity. Most notable were the decreases in the number of patients experiencing hyperkeratosis (30\% SA vs $6 \%$ or $9 \%$ in C), cSCC (19\% SA vs $2 \%$ or $7 \%$ in C) and skin papillomas (15\% SA vs $7 \%$ or $4 \%$ in C). In addition to decreasing the incidence of skin toxicities, the combination treatment was also more efficacious than SA dabrafenib. The response rate and median progressionfree survival in the SA group was $54 \%$ and 5.8 months compared with $50 \%$ or $76 \%$ and 9.2 or 9.4 months, respectively.

Another approach to overcoming paradoxical activation would be to build this selection criteria into the drug development strategy. Whether it is possible to discover such an inhibitor could depend on which model described in the previous section most accurately reflects the true mechanism. For example, if the mechanism involves the inhibition of the catalytic activity of RAF, every RAF kinase activity should induce paradoxical activation. Alternatively, if the mechanism is completely allosteric, then it may be possible to select for an inhibitor that causes a different conformational change in the enzyme that does not induce transactivation of the other RAF protomer. Such an approach has been undertaken whereby inhibitors are selected for potent inhibition of MEK-ERK activation in a BRAF ${ }^{\mathrm{V} 600 \mathrm{E}}$ cell line but decreased potency in the induction of MEK-ERK activation in BRAF wild-type cells (Bollag, 2012). One of these so-called 'paradox-breakers' have recently been described by Le et al (2013). PB04 appeared to display similar potency to vemurafenib in cell lines expressing BRAF $^{\mathrm{V} 600 \mathrm{E}}$ but induced little or no paradoxical activation in RAS mutant and/or BRAF wild-type cells. However, some caution should be taken in drawing absolute conclusions, as the concentrations used in some of the experiments did not cover the entire range of pharmacologically 
active concentrations. Regardless, it does appear that PB04 demonstrated less propensity to induce paradoxical activation than vemurafenib. The advancement of such an inhibitor into human clinical trials has not been reported.

With the intense efforts to discover and develop RAF kinase inhibitors over the last 10 plus years, a wide range of inhibitors with different binding modes (e.g. Type 1 vs Type 2) from different chemical classes have been described (Li et al, 2010). Given the results of Le et al (2013) described above, it may be possible that an inhibitor that induces little or no paradoxical activation already exists. MLN2480 has been described as an inhibitor of BRAF mutant and wild-type tumours and is proposed to be a better inhibitor of RAF dimers than vemurafenib (Galvin, 2012). Although this compound does appear to be more potent at inhibiting MEK and ERK activation in an SK-Mel-2 cells $\left(\mathrm{NRAS}^{\mathrm{Q} 61 \mathrm{R}}\right)$ compared with vemurafenib, it still induces paradoxical activation, and similar to other Type 2 inhibitors (sorafenib, RAF265) inhibits multiple kinases in addition to RAF.

\section{CONCLUSIONS}

RAF inhibitors have made a significant impact on the lives of melanoma patients whose tumours express the BRAF V600E oncogene. As with most other cancer therapeutics, efficacy is associated with side effects and in the case of RAF inhibitors, induction of secondary malignancies is a significant concern. However, it appears that the vast majority of cases with the risk to the patient is relatively low, although the clinical experience with these agents is still very early. The pharmacological behaviour of these inhibitors may not have been anticipated but the observations and follow-up mechanistic studies have led to a deeper understanding of RAF-MEK-ERK signalling. These insights will guide future drug development efforts to create better inhibitors that may be optimised towards a tailored pharmacological profile.

\section{REFERENCES}

Andrews M, Behren A, Chiohn F, Tebbutt N, Do H, Dobrovic A, Mariadason J, Cebon J (2012) Colorectal cancer promoted in a melanoma patient receiving dabrafenib (GSK2118436) in combination with MEK1/2 inhibitor trametinib (GSK1120212). Pigment Cell Melanoma Res 25: 842.

Ascierto PA, Minor D, Ribas A, Lebbe C, O'hagan A, Arya N, Guckert M, Schadendorf D, Kefford RF, Grob J-J, Hamid O, Amaravadi R, Simeone E, Wilhelm T, Kim KB, Long GV, Martin A-M, Mazumdar J, Goodman VL, Trefzer U (2013) Phase II trial (BREAK-2) of the BRAF inhibitor dabrafenib (GSK2118436) in patients with metastatic melanoma. J Clin Oncol 31: 3205-3211.

Bollag G (2012) New strategies for mutation-specific targeting of oncogenic kinases. 103rd Annual Meeting of the American Association for Cancer Research; 31 March-4 April 2012; AACR: Chicago, IL, USA.

Boussemart L, Routier E, Mateus C, Opletalova K, Sebille G, Kamsu-Kom N, Thomas M, Vagner S, Favre M, Tomasic G, Wechsler J, Lacroix L, Robert C (2013) Prospective study of cutaneous side-effects associated with the BRAF inhibitor vemurafenib: a study of 42 patients. Ann Oncol 24: 1691-1697.

Callahan MK, Rampal R, Harding JJ, Klimek VM, Chung YR, Merghoub T, Wolchok JD, Solit DB, Rosen N, Abdel-Wahab O, Levine RL, Chapman PB (2012) Progression of RAS-mutant leukemia during RAF inhibitor treatment. N Engl J Med 367: 2316-2321.

Cebon JS, Flaherty K, Weber JS, Kim K, Infante JR, Daud A, Hamid O, Kefford R, Schuchter LM, Sosman JA, Sznol M, Sharfman WM, Gonzalez R, Andrews MC, Dronca RS, Long G, Little SM, Sun P, Patel K, Mcwilliams RR (2013) Comparison of BRAF inhibitor (BRAFi)-induced cutaneous squamous cell carcinoma (cuSCC) and secondary malignancies in BRAF mutation-positive metastatic melanoma (MM) patients (pts) treated with dabrafenib (D) as monotherapy or in combination with
MEK1/2 inhibitor (MEKi) trametinib (T). J Clin Oncol 31(Suppl): abstr9016.

Chapman PB, Hauschild A, McArthur GA (2011a) Vemurafenib in melanoma with BRAF V600E mutation. N Engl J Med 365: 1448-1450.

Chapman P, Metz D, Sepulveda A, Uehara T, Rustgi A, Nathanson KL, Kim K, Puzanov I, Flaherty K, Sosman JA, Linke R, Schuchter LM, Mcarthur GAmaravadi RK (2012) Development of colonic adenomas and gastric polyps in BRAF mutant melanoma patients treated with vemurafenib. Pigment Cell Melanoma Res 25: 847.

Chapman PB, Hauschild A, Robert C, Haanen JB, Ascierto P, Larkin J, Dummer R, Garbe C, Testori A, Maio M, Hogg D, Lorigan P, Lebbe C, Jouary T, Schadendorf D, Ribas A, O'day SJ, Sosman JA, Kirkwood JM, Eggermont AMM, Dreno B, Nolop K, Li J, Nelson B, Hou J, Lee RJ, Flaherty KT, Mcarthur GA (2011b) Improved survival with vemurafenib in melanoma with BRAF V600E mutation. $N$ Engl J Med 364: 2507-2516.

Cohen PR, Bedikian AY, Kim KB (2013) Appearance of new vemurafenibassociated melanocytic nevi on normal-appearing skin. J Clin Aesthet Dermatol 6: 27-37.

Dalle S, Poulalhon N, Thomas L (2011) Vemurafenib in melanoma with BRAF V600E mutation. N Engl J Med 365: 1448-1450.

Dougherty MK, Muller J, Ritt DA, Zhou M, Zhou XZ, Copeland TD, Conrads TP, Veenstra TD, Lu KP, Morrison DK (2005) Regulation of Raf-1 by direct feedback phosphorylation. Mol Cell 17: 215-224.

Dummer R, Robert C, Nyakas M, Mcarthur GA, Reiney Kudchadkar R, Gomez-Roca C, Sullivan RJ, Flaherty K, Murer C, Michel D, Tang Z, De Parseval LA, Delord JP (2013) Initial results from a phase I, open-label, dose escalation study of the oral BRAF. J Clin Oncol 31(Suppl): abstr 9028.

Flaherty KT, Infante JR, Daud A, Gonzalez R, Kefford RF, Sosman J, Hamid O, Schuchter L, Cebon J, Ibrahim N, Kudchadkar R, Burris HA, Falchook G, Algazi A, Lewis K, Long GV, Puzanov I, Lebowitz P, Singh A, Little S, Sun P, Allred A, Ouellet D, Kim KB, Patel K, Weber J (2012) Combined BRAF and MEK inhibition in melanoma with BRAF V600 mutations. N Engl J Med 367: 1694-1703.

Galvin K (2012) MLN2480: a novel pan-RAF inhibitor for treatment of BRAF mutant and wild-type tumors. 103rd Annual Meeting of the American Association for Cancer Research; 31 March-4 April 2012, AACR: Chicago, IL, USA.

Garnett MJ, Rana S, Paterson H, Barford D, Marais R (2005) Wild-type and mutant B-RAF activate C-RAF through distinct mechanisms involving heterodimerization. Mol Cell 20: 963-969.

Hall-Jackson CA, Eyers PA, Cohen P, Goedert M, Tom Boyle F, Hewitt N, Plant HHedge P (1999) Paradoxical activation of Raf by a novel Raf inhibitor. Chem Biol 6: 559-568.

Hatzivassiliou G, Song K, Yen I, Brandhuber BJ, Anderson DJ, Alvarado R, Ludlam MJ, Stokoe D, Gloor SL, Vigers G, Morales T, Aliagas I, Liu B, Sideris S, Hoeflich KP, Jaiswal BS, Seshagiri S, Koeppen H, Belvin M, Friedman LS, Malek S (2010) RAF inhibitors prime wild-type RAF to activate the MAPK pathway and enhance growth. Nature 464: 431-435.

Hauschild A, Grob J-J, Demidov LV, Jouary T, Gutzmer R, Millward M, Rutkowski P, Blank CU, Miller Jr WH, Kaempgen E, Martín-Algarra S, Karaszewska B, Mauch C, Chiarion-Sileni V, Martin A-M, Swann S, Haney P, Mirakhur B, Guckert ME, Goodman V, Chapman PB (2012) Dabrafenib in BRAF-mutated metastatic melanoma: a multicentre, openlabel, phase 3 randomised controlled trial. Lancet 380: 358-365.

Heidorn SJ, Milagre C, Whittaker S, Nourry A, Niculescu-Duvas I, Dhomen N, Hussain J, Reis-Filho JS, Springer CJ, Pritchard C, Marais R (2010) Kinase-dead BRAF and oncogenic RAS cooperate to drive tumor progression through CRAF. Cell 140: 209-221.

Heinzerling L, Baiter M, Kuhnapfel S, Schuler G, Keikavoussi P, Agaimy A, Kiesewetter F, Hartmann A, Schneider-Stock R (2013) Mutation landscape in melanoma patients clinical implications of heterogeneity of BRAF mutations. Br J Cancer 109: 2833-2841.

Holderfield M, Merritt H, Chan J, Wallroth M, Tandeske L, Zhai H, Tellew J, Hardy S, Hekmat-Nejad M, Stuart DD, Mccormick F, Nagel TE (2013) RAF inhibitors activate the MAPK pathway by relieving inhibitory autophosphorylation. Cancer Cell 23: 594-602.

Hu J, Stites E, Yu H, Germino E, Meharena H, Stork P, Kornev A, Taylor S, Shaw A (2013) Allosteric activation of functionally asymmetric RAF kinase dimers. Cell 154: 1036-1046.

Ishii N, Harada N, Joseph EW, Ohara K, Miura T, Sakamoto H, Matsuda Y, Tomii Y, Tachibana-Kondo Y, Iikura H, Aoki T, Shimma N, Arisawa M, Sowa Y, Poulikakos PI, Rosen N, Aoki Y, Sakai T (2013) 
Enhanced inhibition of ERK signaling by a novel allosteric mek inhibitor, CH5126766, that suppresses feedback reactivation of RAF activity. Cancer Res 73: 4050-4060.

Le K, Blomain ES, Rodeck U, Aplin AE (2013) Selective RAF inhibitor impairs ERK1/2 phosphorylation and growth in mutant NRAS, vemurafenibresistant melanoma cells. Pigment Cell Melanoma Res 26: 509-517.

Li HF, Chen Y, Rao SS, Chen XM, Liu HC, Qin JH, Tang WF, Wang Y, Zhou X, Lu T (2010) Recent advances in the research and development of B-Raf inhibitors. Curr Med Chem 17: 1618-1634.

Lito P, Pratilas C, Joseph E, Tadi M, Halilovic E, Zubrowski M, Huang A, Wong W, Callahan M, Merghoub T, Wolchok J, De stanchina E, Chandarlapaty S, Poulikakos P, Fagin J, Rosen N (2012) Relief of profound feedback inhibition of mitogenic signaling by RAF inhibitors attenuates their activity in BRAFV600E melanomas. Cancer Cell 22: 668-682.

Liu Y, Gray N (2006) Rational design of inhibitors that bind to inactive kinase conformations. Nat Chem Biol 2: 358-364.

Long GV, Trefzer U, Davies MA, Kefford RF, Ascierto PA, Chapman PB, Puzanov I, Hauschild A, Robert C, Algazi A, Mortier L, Tawbi H, Wilhelm T, Zimmer L, Switzky J, Swann S, Martin A-M, Guckert M, Goodman V, Streit M, Kirkwood JM, Schadendorf D (2012) Dabrafenib in patients with Val600Glu or Val600Lys BRAF-mutant melanoma metastatic to the brain (BREAK-MB): a multicentre, open-label, phase 2 trial. Lancet Oncol 13: 1087-1095.

Marais R, Light Y, Paterson H, Marshall C (1995) Ras recruits Raf-1 to the plasma membrane for activation by tyrosine phosphorylation. EMBO J 14: 3136-3145.

Mason C, Springer C, Cooper R, Superti-Furga G, Marshall CJ, Marais R (1999) Serine and tyrosine phosphorylations cooperate in Raf-1, but not B-Raf activation. EMBO J 18: 2137-2148.

Mckay MM, Ritt DA, Morrison DK (2011) RAF inhibitor-induced KSR1/B-RAF binding and its effects on ERK cascade signaling. Curr Biol 21: 563-568.

Menzies AM, Kefford RF, Long GV (2013) Paradoxical oncogenesis: are all BRAF inhibitors equal? Pigment Cell Melanoma Res 26: 611-615.

Nazarian R, Shi H, Wang Q, Kong X, Koya RC, Lee H, Chen Z, Lee M-K, Attar N, Sazegar H, Chodon T, Nelson SF, Mcarthur G, Sosman JA, Ribas A, Lo RS (2011) Melanomas acquire resistance to B-RAF(V600E) inhibition by RTK or N-RAS upregulation. Nature 468: 973-977.

Oberholzer PA, Kee D, Dziunycz P, Sucker A, Kamsukom N, Jones R, Roden C, Chalk CJ, Ardlie K, Palescandolo E, Piris A, Macconaill LE, Robert C, Hofbauer GFL, Mcarthur GA, Schadendorf D, Garraway LA (2012) RAS mutations are associated with the development of cutaneous squamous cell tumors in patients treated with RAF inhibitors. J Clin Oncol 30: 316-321.

Poulikakos P, Zhang C, Bollag G, Shokat K, Rosen N (2010) RAF inhibitors transactivate RAF dimers and ERK signalling in cells with wild-type BRAF. Nature 464: 427-430.

Poulikakos PI, Persaud Y, Janakiraman M, Kong X, Ng C, Moriceau G, Shi H, Atefi M, Titz B, Gabay MT, Salton M, Dahlman KB, Tadi M, Wargo JA, Flaherty KT, Kelley MC, Misteli T, Chapman PB, Sosman JA, Graeber TG, Ribas A, Lo RS, Rosen N, Solit DB (2011) RAF inhibitor resistance is mediated by dimerization of aberrantly spliced BRAF(V600E). Nature 480: $387-390$

Pratilas CA, Taylor BS, Ye Q, Viale A, Sander C, Solit DB, Rosen N (2009) V600EBRAF is associated with disabled feedback inhibition of RAF-MEK signaling and elevated transcriptional output of the pathway. Proc Natl Acad Sci USA 106: 4519-4524.

Rajakulendran T, Sahmi M, Lefrancois M, Sicheri F, Therrien M (2009) A dimerization-dependent mechanism drives RAF catalytic activation. Nature 461: 542-545.

Ritt DA, Monson DM, Specht SI, Morrison DK (2010) Impact of feedback phosphorylation and raf heterodimerization on normal and mutant B-Raf signaling. Mol Cell Biol 30: 806-819.

Rushworth L, Hindley A, O'neill E, Kolch W (2006) Regulation and role of Raf-1/B-Raf heterodimerization. Mol Cell Biol 26: 2262-2272.

Stokoe D, McCormick F (1997) Activation of c-Raf-1 by Ras and Src through different mechanisms: activation in vivo and in vitro. $E M B O J \mathbf{~ 1 6 :}$ 2384-2396.

Su F, Viros A, Milagre C, Trunzer K, Bollag G, Spleiss O, Reis-Filho JS, Kong X, Koya RC, Flaherty KT, Chapman PB, Kim MJ, Hayward R, Martin M, Yang H, Wang Q, Hilton H, Hang JS, Noe J, Lambros M, Geyer F, Dhomen N, Niculescu-Duvaz I, Zambon A, Niculescu-Duvaz D, Preece N, Robert L, Otte NJ, Mok S, Kee D, Ma Y, Zhang C, Habets G, Burton EA, Wong B, Nguyen H, Kockx M, Andries L, Lestini B, Nolop KB, Lee RJ, Joe AK, Troy JL, Gonzalez R, Hutson TE, Puzanov I, Chmielowski B, Springer CJ, Mcarthur GA, Sosman JA, Lo RS, Ribas A, Marais R (2012) RAS mutations in cutaneous squamous-cell carcinomas in patients treated with BRAF inhibitors. $N$ Engl J Med 366: 207-215.

Vin H, Ojeda SS, Ching G, Leung ML, Chitsazzadeh V, Dwyer DW, Adelmann CH, Restrepo M, Richards KN, Stewart LR, Du L, Ferguson SB, Chakravarti D, Ehrenreiter K, Baccarini M, Ruggieri R, Curry JL, Kim KB, Ciurea AM, Duvic M, Prieto VG, Ullrich SE, Dalby KN, Flores ER, Tsai KY, Davis R (2013) BRAF inhibitors suppress apoptosis through offtarget inhibition of JNK signaling. Elife 2: e00969.

Wan PT, Garnett MJ, Roe SM, Lee S, Niculescu-Duvaz D, Good VM, Jones CM, Marshall CJ, Springer CJ, Barford D, Marais R (2004) Mechanism of activation of the RAF-ERK signaling pathway by oncogenic mutations of B-RAF. Cell 116: 855-867.

Wilhelm SM, Carter C, Tang L, Wilkie D, Mcnabola A, Rong H, Chen C, Zhang X, Vincent P, Mchugh M, Cao Y, Shujath J, Gawlak S, Eveleigh D, Rowley B, Liu L, Adnane L, Lynch M, Auclair D, Taylor I, Gedrich R, Voznesensky A, Riedl B, Post LE, Bollag G, Trail PA (2004) BAY 43-9006 exhibits broad spectrum oral antitumor activity and targets the RAF/MEK/ERK pathway and receptor tyrosine kinases involved in tumor progression and angiogenesis. Cancer Res 64: 7099-7109.

Zimmer L, Hillen U, Livingstone E, Lacouture ME, Busam K, Carvajal RD, Egberts F, Hauschild A, Kashani-Sabet M, Goldinger SM, Dummer R, Long GV, Mcarthur G, Scherag A, Sucker A, Schadendorf D (2012) atypical melanocytic proliferations and new primary melanomas in patients with advanced melanoma undergoing selective BRAF inhibition. J Clin Oncol 30: 2375-2383.

This work is licensed under the Creative Commons License. To view a copy of this license, visit http://creativecommons. org/licenses/by-nc-sa/3.0/ 